\title{
THE EFFECT OF STRUCTURAL ELEMENTS ON THE INTERIOR ARCHITECTURAL SPACE
}

\author{
Khaled Ali Mohamed Ali Zid \\ Department of Architecture, Faculty of Engineering in Mataria - Helwan University
}

\section{INTRODUCTION}

Architectural design is done by a designing work group headed by an Architect as all the information related to work shall be reported to him in order to perform the designing process. One of the main determinants of practicing the designing process is the process of creating an economical structural system that integrates with the architectural creativity where structure is one of the main reasons of the spatial creativity and architectural forming. Structure may be a spark of the imaginative creativity in the architectural field.

The relationship between structure and architectural space was between the clarity of the effect of the structural system on the architectural space -functionally, aesthetically, or bothand hiding this effect. The study is concerned with studying the integration relationship between the components of the structural system and the components of the interior space.

\section{RESEARCH HYPOTHESIS}

The research supposes the probability of creating an evaluative form to test the effect of the design efficiency of the structural elements on the Interior architectural space Efficiency in achieving the Physical and spiritual requirements of users, so that the form can be applied during the phases of initial design in order to define the level of interaction and evaluate the different alternatives of solutions to select the best one. This form may be applied on current buildings as well in order to measure the positive and negative aspects from which trends of increasing their efficiency will be presented.

\section{Research Objectives}

An attempt to develop an evaluation form that evaluates the interchangeable relationship between structural elements and interior space. In order to achieve this goal, a set of secondary goals shall be achieved. This set contains the following:

1- Defining the spatial system and its components along with the role of the structural system within this system.

2- Defining the structural system and the involved elements that have an effect on the system.

3- Monitor the relationship between structural patterns and how these patterns interact with the interior space throughout the history.

\section{RESEARCH STRUCTURE:}

The research is divided into two main parts:

Theoretical Study: The theoretical study aims at setting a vision of the theoretical formulation of the suggested Evaluation Form. This can be done through defining the structural, spatial systems and their interchangeable relationship.

Analytical Study: The analytical study examines the Evaluation Form by applying it on successful International architectural forms in order to prove or disprove the theory by the usage of the descriptive analytical method. 


\section{THEORETICAL STUDY: \\ 1- INTERIOR ARCHITECTURAL SPACE}

Buildings are considered as a cover/layer of space that serves various human activities. On performing these activities, Man needs special spatial and environmental requirements. Thus, before commencing the designing process, the Architect shall be aware of the User's physiological, psychological comfort requirements and his future requirement within and between the interior spaces. ${ }^{1}$ This aims at studying the interior space relationship system and at which place does the structural elements stand from this system.

\section{1-1- Physical Elements of Interior space}

These elements are considered as the designer's tools to formulate $\&$ shape any space into a standalone shape. These elements are ${ }^{2}$ :

1-1-1- Architectural Elements

Architectural elements mean the elements surrounding the space. These are responsible for the final formulation of the space. These elements include: (floors, walls, ceilings).

\section{1-1-2- Structural Elements}

These elements forms the structural system, which is primarily responsible for formulating the interior space. Structure plays a key role in achieving the requirements of the architectural space with a technological efficiency that fits the modern age, available materials, manufacturing methods, and structural elements, which are: (Vertical Elements Horizontal Elements - Structural Surface).

\section{1-1-3- Elements of Spatial Transition}

These are the transitional elements in the Interior design (corridors, stairs, windows, doors) as they transfer visually \& physically the relationship between space and other and the relationship between indoors and outdoors. The size and shape of these openings affect the visual integration of surface of the wall and sensing the content it covers.

\section{1-1-4- Furnishing Elements}

The choice and order of furnishing elements in each spatial area of the building are the most important elements in the interior design. The way of using these elements affect the usage of space and its perception.

\section{1-1-5- Technical Systems}

These electromechanical systems are used in any space for the comfort of the user. These systems shall be designed in an integrated manner with the building's structural system.

\section{2- INTERIOR SPATIAL SYSTEM}

The system is defined as an interaction between parts associated to each other in order to achieve certain goals. Spatial system is a set of required requirements to configure interior space for the physical and spiritual comfort of users. This system consists of a number of systems as described in Figure (1); these systems are ${ }^{3}$ :

\section{2-1- Human System}

It intended to be the system that shapes the Human's Public thought in the society. This system is consisted of the following:

\section{2-1-1- Human Environment}

It the environment that shapes the thought and personality of the individual along with the physiological, mental and social formation. This environment is divided into ecological and cultural environments.

\section{2-1-2- Human Structure}

This structure is divided into three structures; physical structure (is defined as the inner systems and organs of the human body which integrates one another in a functional balance), psychological structure (is defined as the human psychological \& instinctual phenomena), and mental structure (is

\footnotetext{
${ }^{1}$ Mourad Abd Al-Kader: Development of architectural space Concept - Masters Degree - Architecture Department - Faculty of Engineering, Cairo University in 1972 (P. 31, P. 32).

2 - Francis DK.Ching :Interior Design Illustrated, Van Nostrand, Reinhold, New York ,1983, p164-0167.

3 - Ali Ra'fat: Environment \& Space - Triad Architectural Creativity - Inter Consult Research Center, Al-Ahram Printing Presses, Cairo in 1996 (P. 29).
} 
defined as the intellect that differs Human from other creatures) and how it deals with environmental circumstances. This aims at determining the role of the cover, interior and exterior architectural space in configuring these circumstances to best suit the human. ${ }^{1}$

\section{2-2- Functional System}

Function is the first measure to decide on the success of the interior space. In order to achieve the optimal function within space, users' requirements and activities to be performed within this space shall be analyzed, these are $^{2}$ :
A- Users Requirement
B- Activity Requirements
C- Dimensional Requirements
D- Furnishing Requirement
E- Safety Requirements

\section{2-3- Environment Comfort System}

Man needs to control the interior surrounding of space by natural or artificial methods in order to achieve his physical comfort. $^{3}$
A- Climatic Comfort
B- Lighting Comfort
C- Acoustical Comfort

\section{2-4- Aesthetic System}

As the key purpose of interior architectural space was protection against natural circumstances and performing a particular function, but still it needs to achieve a visual and psychological pleasure to express the society with its customs, traditions, and values. Aesthetic System is the one to promote and develop the architectural work from a state of being a mere building into a work of art.

The Aesthetic System can be divided into three types, as follows ${ }^{4}$ :

\section{A- Sensuous Aesthetic \\ B- Emotional Aesthetic \\ C- Intellectual Thoughts}

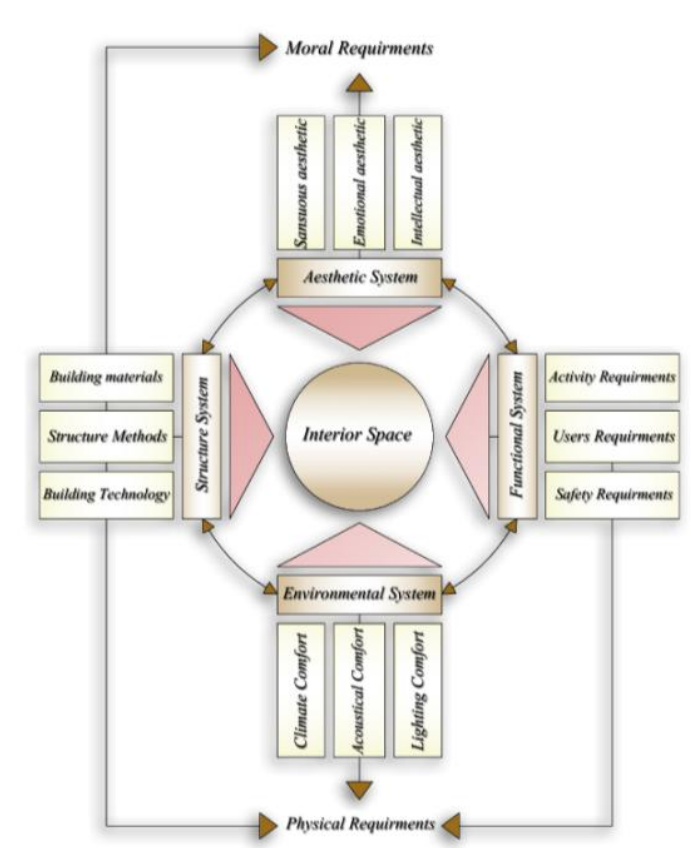

Fig. 1: Interior Spatial System - Source: Researcher

The cover of the Courtyard of Al-Masjid An-Nabawi is one of the examples that clarify the three Aesthetic types. In this example, the Sensuous Aesthetic appears in the usage of materials-known to this environment along with the usage of a neutral color; white color. The Emotional Aesthetic appeared in the structural system used, which is presented in "tents" because of its historical and environmental value towards the user. The Aesthetic thought is represented in the successful role applied by these tents in the small-sized structural elements and the technology of using membrane at night with the usage of formation items inspired from the Al-Masjid an-Nabawi's formation items as shown in Figure no. (2).

\footnotetext{
1 - Same previous resources, P. 44, P. 54, P. 62.

2 - Hind Al-Sayed Othman: Spatial Energy and Total Thermal Comfort, PhD Degree, Architecture Department, Faculty of Engineering, Cairo University in 2004, P. 182.

3 - Same previous resources, P. 30, P. 31.

4 - Erfan Samy: "Theory of Architectural Functionality" - Dar Al Marref in 1966 - P. 14 to P. 17.
} 


\section{THE EFFECT OF STRUCTURAL ELEMENTS ON THE INTERIOR ARCHITECTURAL SPACE}

\section{2-5- Structural System}

Structure is a basic component in the architectural space Components, as it is primarily responsible for the configuration of the spatial content to perform the required function on strength \& economic basis. The physical elements of the structural system consist of: ${ }^{1}$

A- Building Materials Building materials are the physical component of structure and their properties are responsible for the resulted structural configurations. The more Materials Science is developed and new properties and materials are discovered, the more structural possibilities are developed, subsequently new spatial formations appear.

B- Structural methods: These are various structural styles and methods created as a coverage pattern for different spaces; each system has its own properties that vary from other systems. These systems are divided according to stress resulting from them.

C- Building Technology Building technology and the implementation methods used in structure are associated with the structural patterns and the materials used in construction. It is considered as the mean of forming the general skeleton of the building.

\section{3- COMPONENTS OF THE STRUCTURAL SYSTEM}

Structural design goes through two phases; Qualitative \& Quantitive phases. The Qualitative phase is the phase in which the predicted structure type to be used, its physical and shape are determined. This phase is only related to the Architect. The Quantitive phase is the phase in which the accounting necessary to the suggested structural system is conducted. This phase is related to the Civil Engineer. For the architect to perform his role, he shall know the requirements of the structural system, Figure (3):

\section{3-1- Aesthetic and Functional Requirements}

Each structural system shall achieve two key points; beauty "spiritual requirements" alongside with achieving the technology and functionality "physical requirements."

\section{3-1-1- Physical Requirements}

Physical requirements mean the compatibility of structure with the functions of the building or the specifications of space on the qualitative \& quantitive levels, by achieving the following:

A- Strength Strength can be achieved by keeping a proportion between "height and thickness" and "amount of materials and the length of its extension in the air." This is required in any building. The strength of the building might mean its flexibility or strength. There is no contradiction between flexibility and strength, such as: the bow; it's strong and flexible at the same time.

B- Function: Function is the key factor that determines the shape of the building. It is noticed that the type of mere functional buildings, such as: garages and other buildings where there is no functionality, such as: cenotaph and an example about this is the thickness of the stems of trees is decreased, as it grows higher in order to resist winds. Additionally, in winter, most trees drop their leaves in order to reduce the wind-prone space and reducing the load as this allows the sunrays to reach the tree in order to perform its function ${ }^{2}$.

C- Economic Efficiency: Economic Efficiency is one of the key factors influencing the design of facility, and choice of building materials. The typical economic-efficient structural system is the one that achieves the required space, putting the following into consideration ${ }^{3}$.

* Efficiency of Material Usage

\footnotetext{
1 - Omar Ben Al-Hashemy: "The effect of Modern Technology on the Architectural formation of Interfaces in the Arab World" - Masters Degree, Department of Architecture, Faculty of Engineering, Cairo University in 2000 (P. 81, P. 82).

2 - Yehia Abd-Allah:- Lectures of Architecture theories, Second Year, Department of Architectural Engineering, Faculty of Fine Arts, Helwan University.

3 - Ali Ra'fat: Structural Creativity in Architecture - Triad Architectural Creativity - Inter Consult Research Center, AlAhram Printing Presses, Cairo in 1996 (P. 43, P. 44).
} 


\section{THE EFFECT OF STRUCTURAL ELEMENTS ON THE INTERIOR ARCHITECTURAL SPACE}

* Compatibility of implementation requirements with available employment, materials, and technology

* Cut down Project's implementation period

* Facility's age

* Self-Weight

\section{3-1-2- Aesthetic Requirements}

These are the requirements that develop the psychological and visual pleasure to the receiver. These are as follows:

\section{3-1-2-1- Sensuous Aesthetics}

Static \& Dynamic Balance Sense of balance is an inherent sense in human as he feels it in himself and his surroundings, especially, the structural balance of the building, which has to be clear for everyone to give the sense of security.

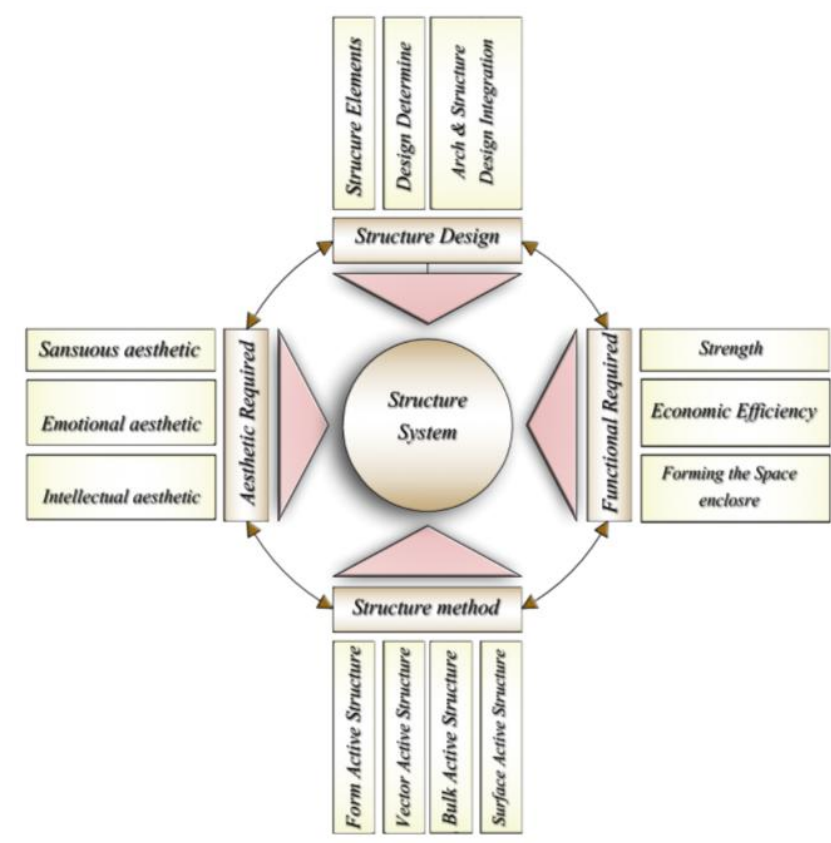

Figure 3: structure system inside the architectural space - Source: Researcher

Balance can be achieved by many methods, ${ }^{1}$ which are:

- Static Stabilization by Accumulation Weight is transferred by direct accumulation as a result of the weight resulting from gravity.

- Stabilization by Stiffness Also known as cohesion or physical continuity, i.e.: the building with its girders and columns are cohered to resist the load and transfer it to the bases then to the ground (like the structural skeleton).

- Stabilization by the continuous engineering unit As loads are transformed into axial stress flowing inside the balanced facility to the ground, such as: Vault Structure.

- Stabilization by Softening and Zero Stiffness As the covered material is soft to take the suitable position that fits to transfer the axial stress by pressure or by tension to the ground, such as: tension cable or tension membrane.

- Technological Stabilization: Like the mechanical backstops, cylindrical, or coned springs that gain lifting or pressing strength as a result of tension or previous pressure in the direction of loading.

Sense of Security: Structural system of the architectural building is primarily responsible for the provision the sense of security for the receiver when viewing or using the building.

Flexibility: Flexibility -in its use qualitatively \& quantitively- is one of the important requirements of the modern spaces. Thus, it is preferred to enable the possibility of assembly, disassembly, transportation, removal, and addition in the used structural system.

Lighting and Ventilation: Architects attempted to develop the structural sector in order to create a possibility for upper and side lighting until they reached currently to a reticulated structural skeleton that can be all covered by glass.

\section{3-1-2-2- Aesthetics Thought}

These are very clear in facilities with the designing goal of construction, such as: cenotaph and towers. Aesthetics can be achieved by many methods, such as: incorporation of function in the structure, such as: a shell, or incorporation of the structure in the function, such as: the rabbit.

\section{3-1-2-3- Emotional Aesthetics}

Not everything resulting from structure might be accepted aesthetically, unless an architectural artistic sense is added to it. On the other hand, facilities that are not suitably structured cannot be disapproved aesthetically, such as: Pharaonic Architecture, as it has a high value but it is not

\footnotetext{
1 - The same previous resource, P. 41:
} 
THE EFFECT OF STRUCTURAL ELEMENTS ON THE INTERIOR ARCHITECTURAL SPACE

structurally suitable. The expressive relationship between the structural skeleton and the building was swinging throughout ages.

\section{3-1-3- Structural Patterns}

Structural Patterns are classified according to the resulting stress in the system: When the structural skeleton is exposed to particular loads, it transforms to particular stress (tension - pressure bending). Structural patterns are classified according to the produced types of stress. This method is the most accurate classification that is addressed by the Study. Thus, types of structural patterns are":

1- Form active structure systems "structure systems in single stress condition": A structure that primarily affects by configuring the shape of the material. Table (1) demonstrates the structural types listed in this system.

2- Vector-active structure systems: "A structure that primarily affects by Pressure and Tension members." Table (2) demonstrates the structural types listed in this system.

3- Bulk active structure systems (under the effect of moments): "A structure that affects through the mass of the material and its continuity." Table (3) demonstrates the structural types listed in this system.

4- Surface-Active Structure system: "A structure that primarily affects through the continuity of surface." Table (4) demonstrates the structural types listed in this system.

5- Vertical Structure system: "A structure that primarily affects through transferring the loads vertically."

\section{4- RELATIONSHIP BETWEEN SPATIAL AND STRUCTURAL SYSTEMS \\ This study consists of two phases:}

First Phase: Monitor and document the historical relationship between both systems.

Second Phase: An attempt to analyze the relationship between both systems theoretically through the information available from the study to discover the element of relevance between the spatial system and structural system, from which the suggested evaluation form will be suggested.

\footnotetext{
${ }^{1}$ Enge, Heino: Structure systems, DVA, University of Minnesota,1965 p
} 
THE EFFECT OF STRUCTURAL ELEMENTS ON THE INTERIOR ARCHITECTURAL SPACE

Table (1): Form active structure systems Source: Researcher

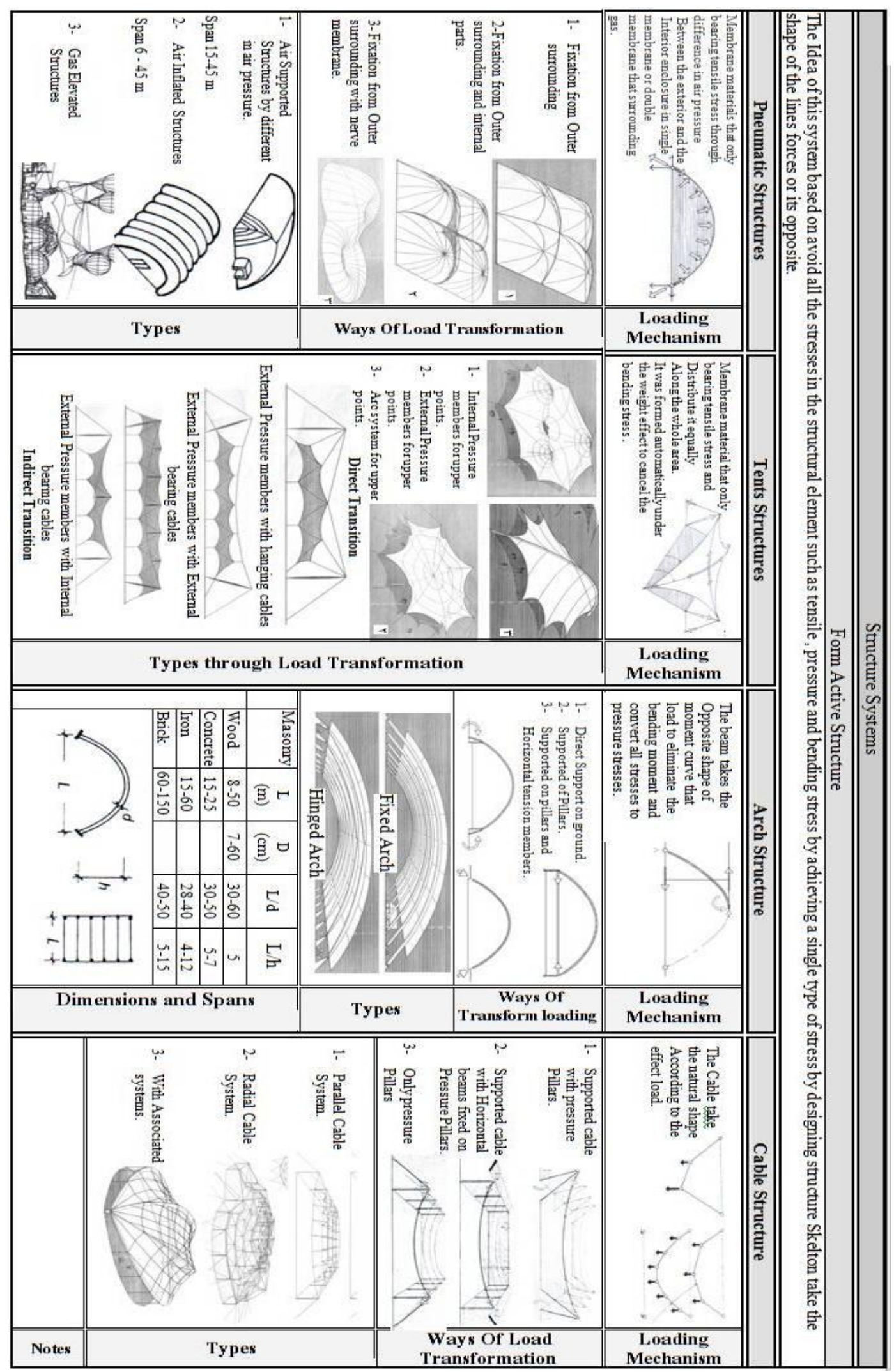


THE EFFECT OF STRUCTURAL ELEMENTS ON THE INTERIOR ARCHITECTURAL SPACE

Table (2): Vector-active structure systems Source: Researcher

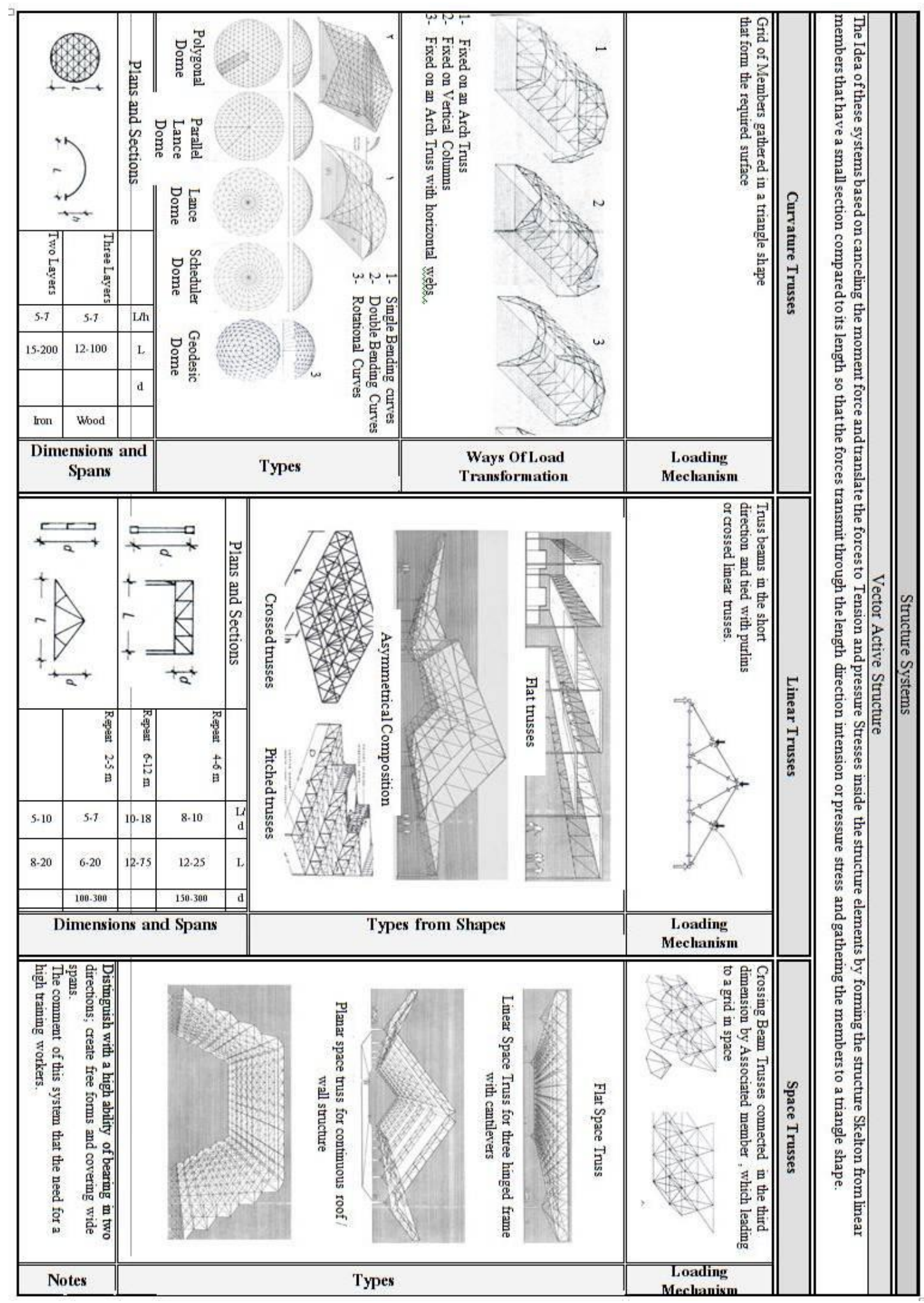


THE EFFECT OF STRUCTURAL ELEMENTS ON THE INTERIOR ARCHITECTURAL SPACE

Table (3): Bulk active structure systems Source: Researcher

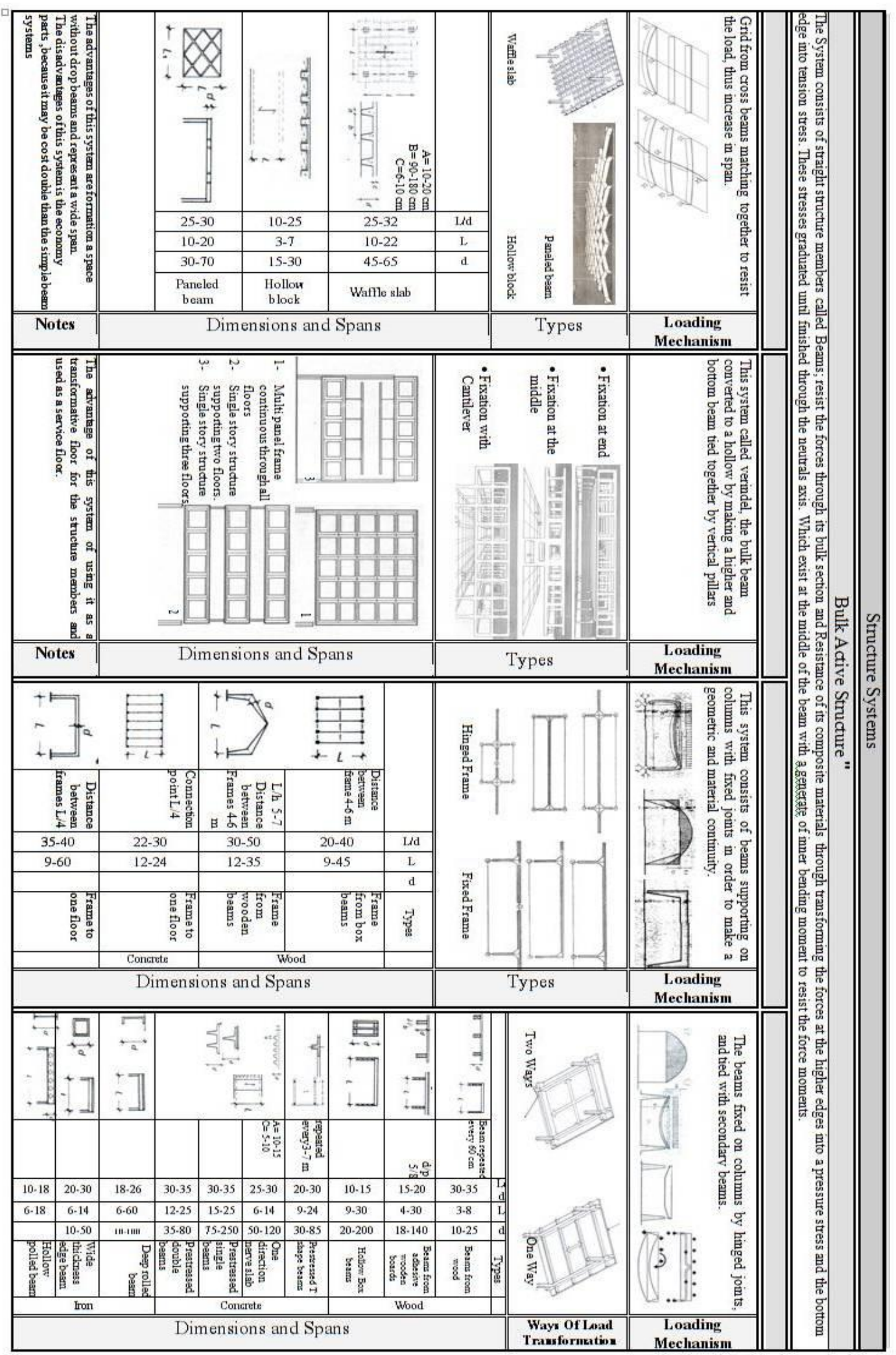


THE EFFECT OF STRUCTURAL ELEMENTS ON THE INTERIOR ARCHITECTURAL SPACE

Table (4): Surface-Active Structure system Source: Researcher

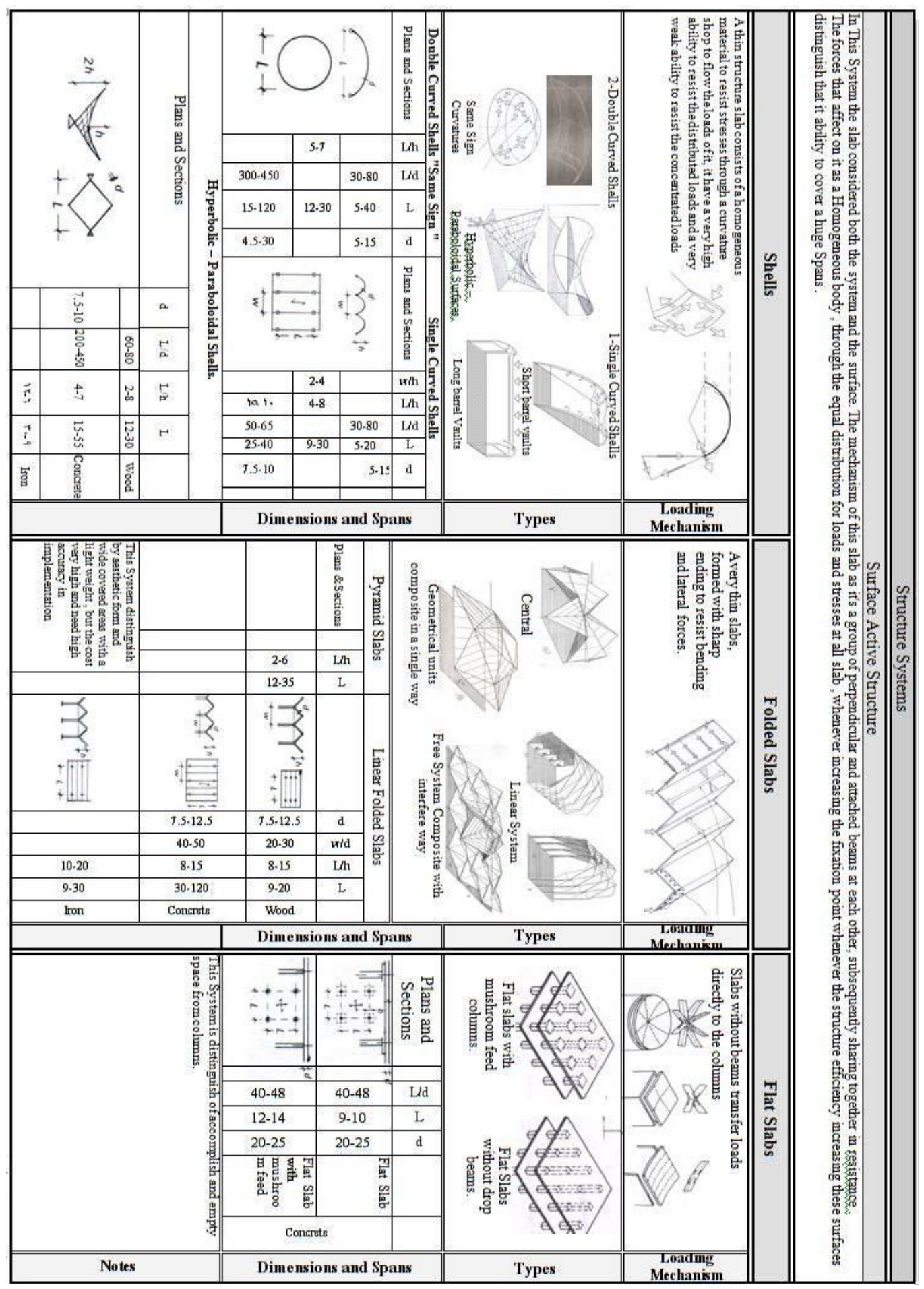

Historical Relationship Between Structure And Architectural Space

The relationship between the interior architectural space and structure went through three thinking phases :

\section{- The Phase of Single Thought:}

1 - Dr. Moustafa Adly Baghdady, "Changing Ideals In Architecture"

- Third International Conference, Azhar University, Faculty of Engineering in 1993 AD. P. 20 


\section{THE EFFECT OF STRUCTURAL ELEMENTS ON THE INTERIOR ARCHITECTURAL SPACE}

The development of designing thinking of the architectural space in terms of height, spans, and internal ratios of elements shaped the space resulted from the capabilities of building materials and structural patterns used. In most eras of single thought, the structural behavior has controlled the interior space. The structural system used was considered as a material that withstands pressure "for columns," such as: stones, bricks, and concrete. In addition, a material that withstands tension, such as: wood "for ceilings." Surface-Active Structure systems developed from the usage of tiled stones, to the usage of flat trusses loaded with wooden surfaces, until it developed to the usage of domes and vaults made of stones, bricks, or concrete.

\section{- The Phase of Dual Thought:}

Two architecture trends appeared during this phase.

A- First Trend: is the trend of traditional architects who tried preserving former heritage without any modification. They used natural local materials in building. This trend did not persist for too long as a result of a need for functional spaces with different uses and activities.

B- Second Trend: led to a new technological revolution with the discovery of new structural materials, which are reinforced concrete and steel. These materials characterized with high capabilities of resisting tension and pressure together throughout previous ages. This led to a new architectural horizons and appearance of new structural patterns that suit the capabilities of these materials that has become internationally known. This helped the reformation of spaces using a new thought based upon structural thought.

\section{- The Phase of Thought Multiplicity:}

The mechanical viewpoint was removed from society and individual multiplicity appeared in all fields of life. Each group was characterized by its own thought in a manner that affected architecture by the appearance of various different trends of thought, such as:

A- The continuity of direct interaction between space and structure with the usage of building materials and international technology in structure.

B- An indirect interaction with interior architectural space with a false expression about building materials.

C- The relationship between architectural space and structure swung according to the personal thought of the architect.

\section{4-2- Suggested Evaluation Form}

Previous theoretical analysis helped in determining the elements with relevance between structural system and interior architectural space system, from which an evaluation form can be created to evaluate this relationship. This form includes all the previous elements. It can be used in the evaluation and measurement of design efficiency of structure on the interior architectural space in any architectural building whether an already built one or a building in the designing phase by assuming the stability of all the parameters of the spatial system excluding the structural system in order to measure and evaluate this relationship.

The suggested form consists of three basic elements determining the relationship between the structural system and the spatial system as illustrated in Table (5) as follows:

1- Structural Requirements: Consist of 9 elements for measurement.

2- Structure interaction with physical requirements of space: Consist of 16 elements for measurement.

3- Structure interaction with aesthetic requirements of space: Consist of 18 elements for measurement.

Total measurement elements: 43 element. The evaluation of each element takes place with a digital value of four values: 0 - 1 - 2 - 3 where:

\section{0: "No Interaction" "Strong Interaction" \\ 1: "Weak Interaction" 2: "Intermediate Interaction"}

The measurement of any project will take place by comparing it to a standard form that is supposed to obtain highest points - The 43 elements obtain 128 points as demonstrated in Table (5).

\begin{tabular}{|c||c||c|}
\hline $\begin{array}{c}\text { Linked elements } \\
\text { between both } \\
\text { systems: }\end{array}$ & $\begin{array}{c}\text { No. of } \\
\text { Measuring } \\
\text { Points }\end{array}$ & $\begin{array}{c}\text { Highest } \\
\text { Measuring } \\
\text { Value }\end{array}$ \\
\hline \hline
\end{tabular}




\section{THE EFFECT OF STRUCTURAL ELEMENTS ON THE INTERIOR ARCHITECTURAL SPACE}

The results expected to be obtained from applying the form are:

- Measurement of the level of interaction between the structure and interior space in an accumulative manner.

- Measurement of the interaction of each requirement of the three interaction requirements.

- Defining the performance level of each element of the measurement elements.

\begin{tabular}{|c|c|c|}
\hline $\begin{array}{c}\text { Structural } \\
\text { Requirements }\end{array}$ & 9 & 26 \\
\hline \multicolumn{3}{|c|}{ Table (5): Components of the Standard Form 18} \\
\hline Requírements & & to \\
\hline $\begin{array}{l}\text { Interaction with } \\
\text { Aesthetic } \\
\text { Requirements }\end{array}$ & 18 & 54 \\
\hline Total & 43 & 128 \\
\hline
\end{tabular}

- Conduct a statistical study comparing different architectural buildings subject to the application of the form. The study assumes the possibility of applying this form on existing projects or projects during the initial designing phase in order to reach the optimal solution.

\section{ANALYTICAL STUDY:}

\section{5- EXAMINING THE EVALUATION FORM}

\section{5-1- Introduction}

Descriptive analytical method, that studies and describes the properties and the dimensions of a phenomenon of phenomena in a certain frame or position, is used. Necessary information and data about each phenomenon are collected, arranged and analyzed through this method to reach the causes and reasons of this phenomenon along with the analysis of factors controlling them. This results in concluding results that can be generalized in the future in addition to interpreting these results whether to prove or disprove certain suggestions assumed by the researcher in the beginning of the study.

\section{5-2- Samples}

Features and specifications of samples will be used in examining the form were identified as follows:

- Selected projects with public activities, such as: administrative, entertainment, commercial, and cultural spaces.

- Internationally known architects design these projects.

- These projects or most of them has been awarded in international competitions.

Three international projects were chosen as demonstrated in tables. 
THE EFFECT OF STRUCTURAL ELEMENTS ON THE INTERIOR ARCHITECTURAL SPACE

Table (6): Evaluation of the Project "Swiss Re Tower"

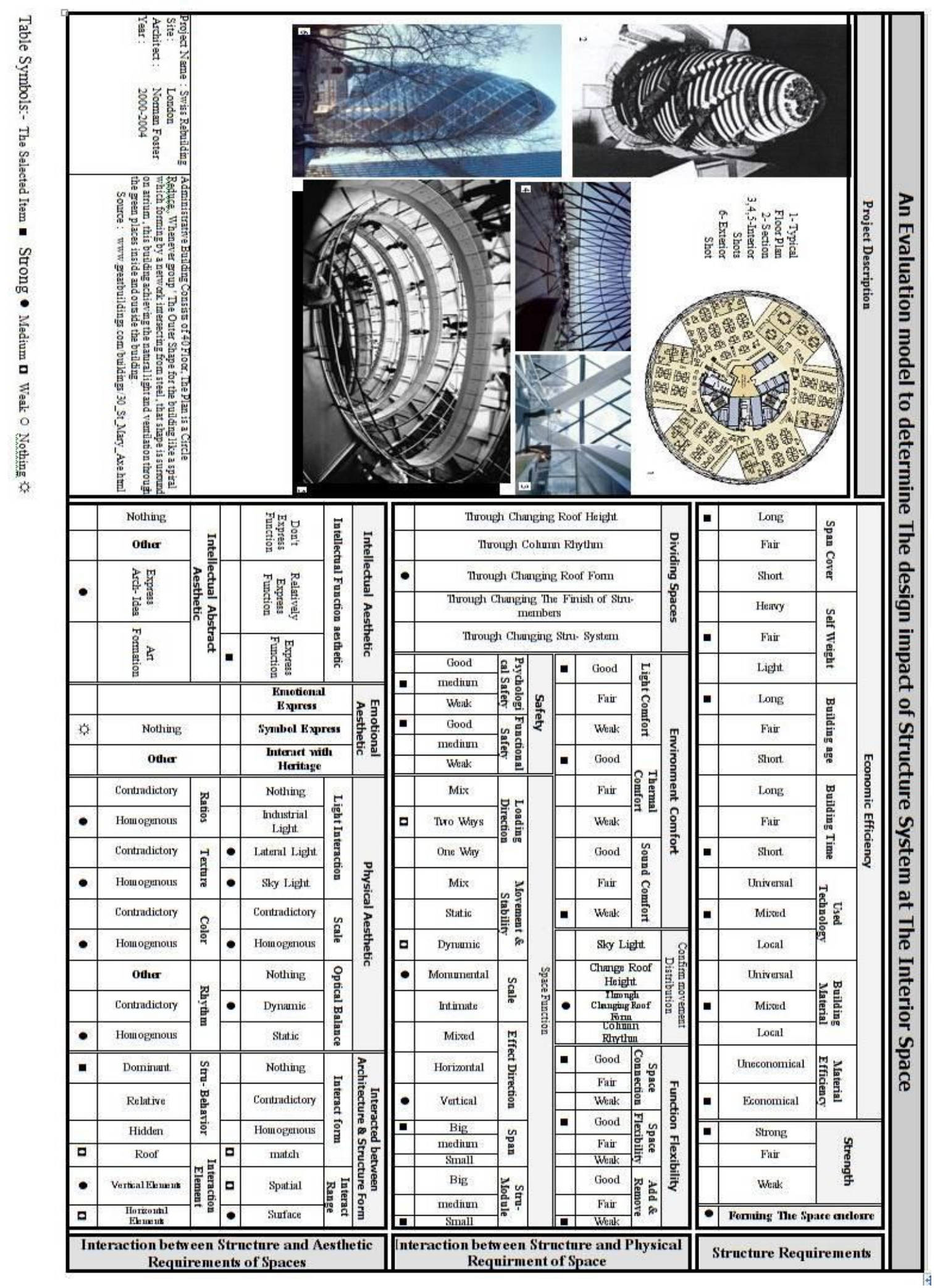


THE EFFECT OF STRUCTURAL ELEMENTS ON THE INTERIOR ARCHITECTURAL SPACE

Table (7): Evaluation of: "Library of Alexandria (Bibliotheca Alexandrina)"

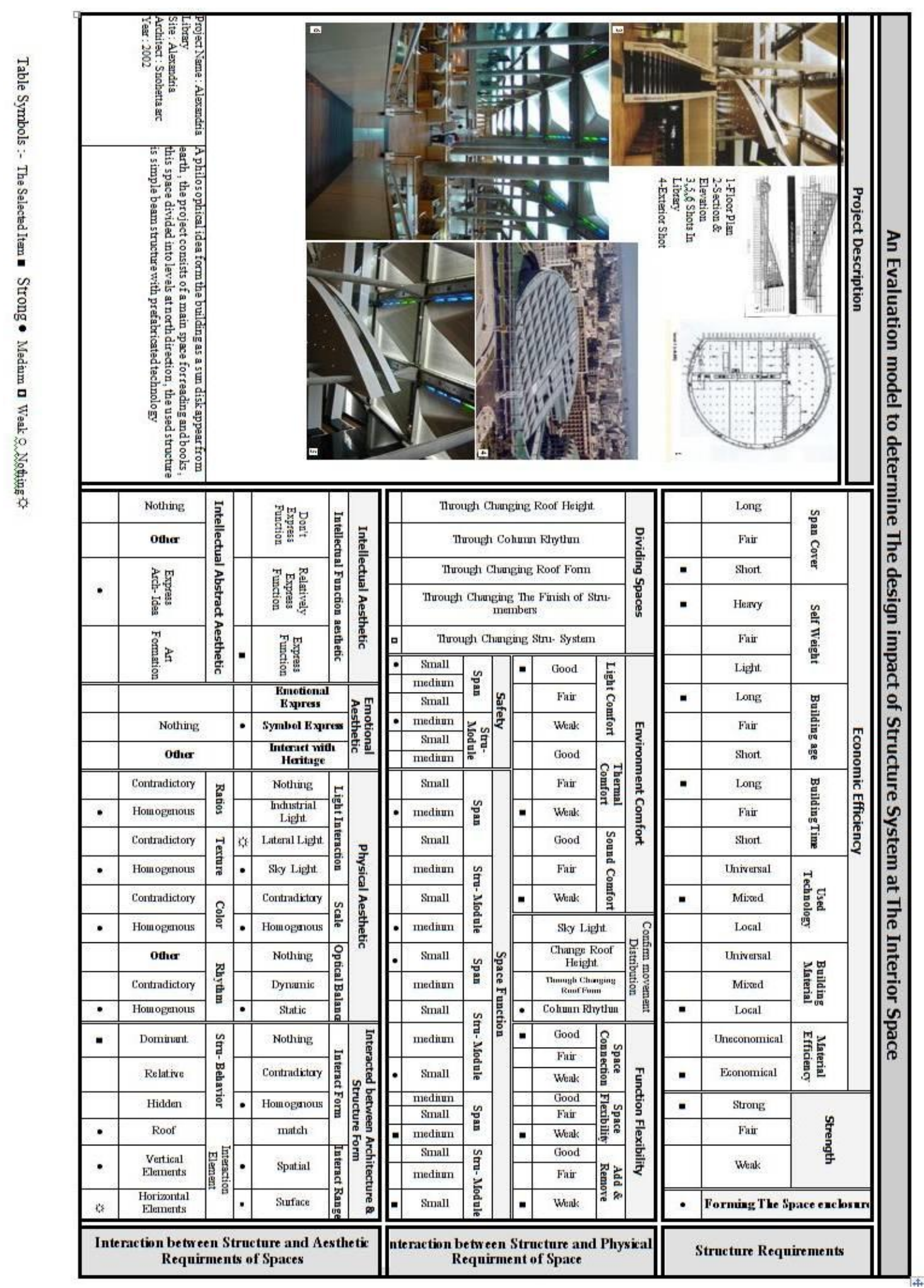


THE EFFECT OF STRUCTURAL ELEMENTS ON THE INTERIOR ARCHITECTURAL SPACE

\section{5-3 - Results of examining the Evaluation Form \\ 5-3-1 Average Detailed Structural Requirements}

Figure (4) displays a comparison between average values of interaction elements of structural requirements for each building with the standard form. The following is concluded:

1- Most interactive elements are: the elements of formation of spatial content and strength and the weakest interactive element is self-weight.

2- The diagram enables the identification of the following: (identify the efficiency of each element of the interaction elements - compare the performance of sample elements between one another).

\section{5-3-2- Average Detailed Financial Requirements}

Figure (5) displays a comparison between average values of interaction elements of structure and physical requirements of total number of samples with the standard form. The following is concluded:

1- Most interactive element is the element of functional security and the weakest interactive element is the element of removal and addition.

2- The diagram enables the identification of the following: (identify the efficiency of each element of the interaction elements - compare the performance of sample elements between one another).

\section{5-3-3- Average Detailed Aesthetic Requirements}

Figure (6) displays a comparison between average values of interaction elements of structure and aesthetic requirements of total number of samples with the standard form. The following is concluded:

1- Most interactive element is the element of color and the weakest interactive element is the element of emotional beauty.

2- The diagram enables the identification of the following: (identify the efficiency of each element of the interaction elements - compare the performance of sample elements between one another).

\section{5-3-4- Total Average}

Figure (7) displays a comparison between the ratios of total requirements per each sample with the elements of standard form.

Figure (8) displays a comparison between the ratios of total requirements for all samples collectively with the ratios of the elements of standard form. This figure demonstrates that structural requirements obtained $80.8 \%$, functional requirements obtained $77 \%$, and aesthetic requirements obtained $88 \%$ of the standard form.

Figure (9) displays a comparison between total samples and total standard form. It demonstrates that samples achieved the percentage of $82.5 \%$ of the standard form. This percentage is high which proves the success of the form in the measurement process and its adequacy for practical application.

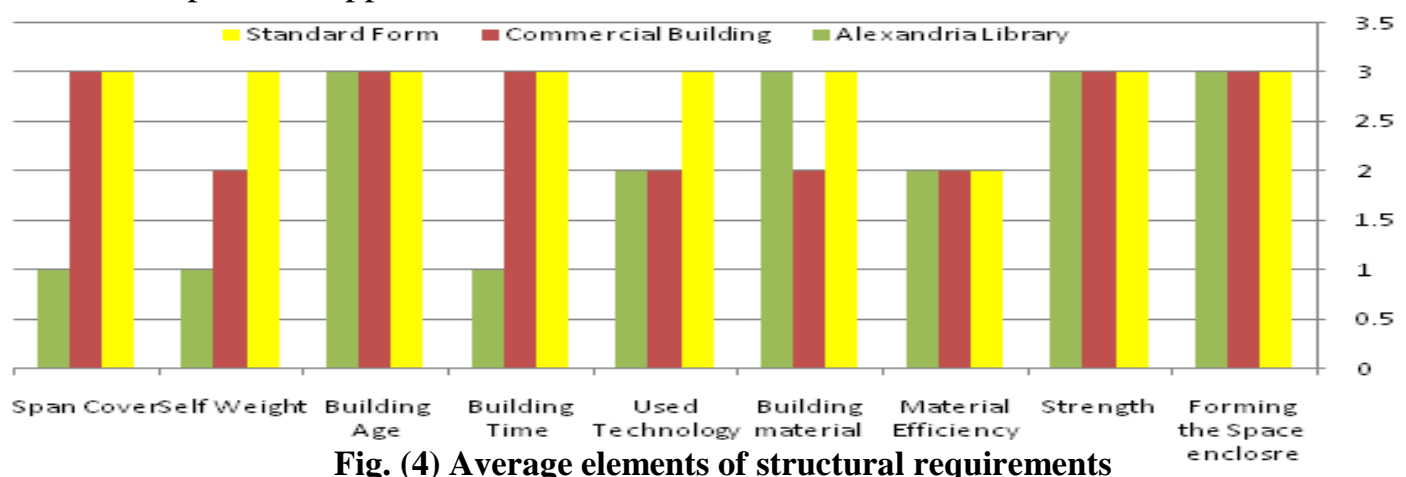

Fig. (4) Average elements of structural requirements 


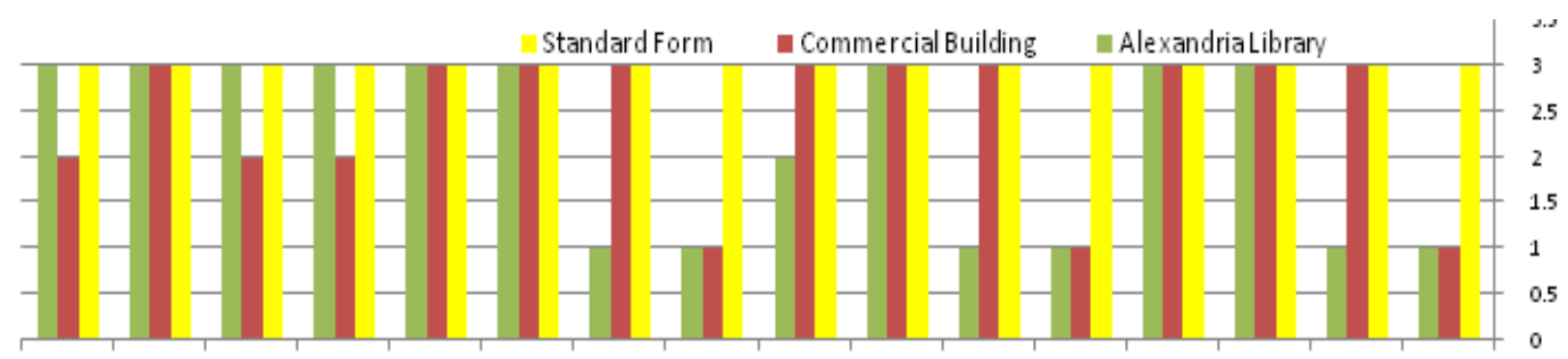

Functional Safety Morement Effect Direction Strut Module Light Comfort Sound comfort Space connection Added \& Pemore \&stability Figure (5) Average elements of functional requirements

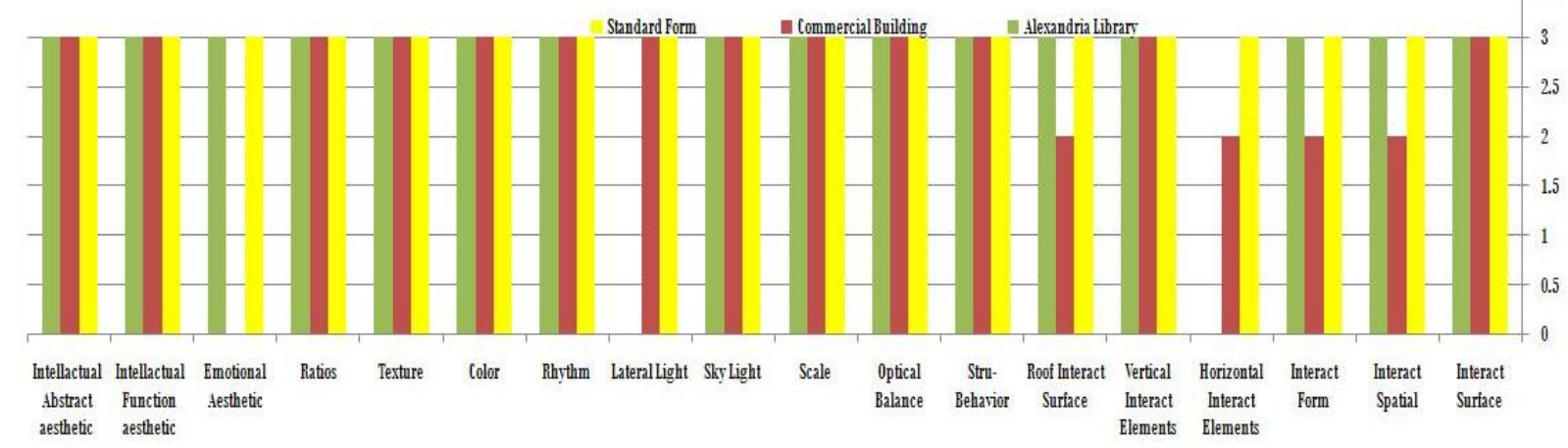

Figure (6) Average elements of aesthetic requirements

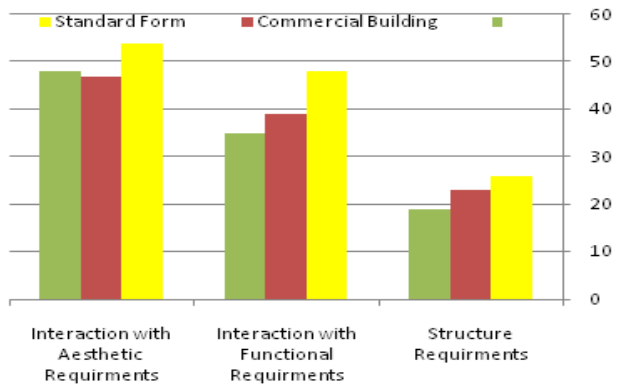

Figure (6) Average of requirements per each sample with the standard form.

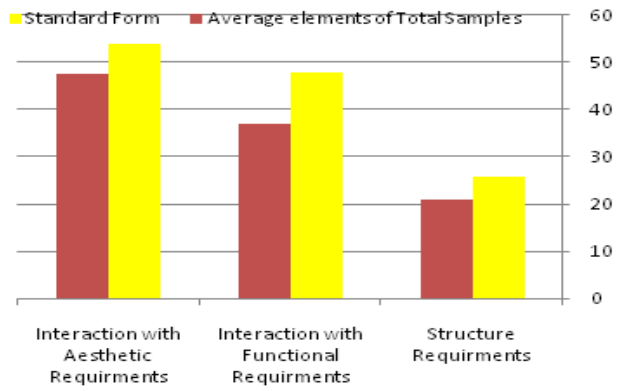

Figure (7) Average elements of

Total samples requirements

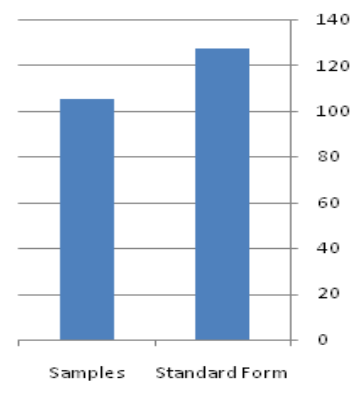

Figure (8) Average elements of Total samples

\section{6- RESULTS \& RECOMMENDATIONS}

\section{6-1- Results:}

1- Research study -through the theoretical \& analytical parts- confirmed the validity of the theory of the possibility of creating an evaluation form to measure the interchangeable relationship between the spatial and structural systems whether on existing buildings or designing process to compare the alternatives or evaluate the suggested alternative solution itself.

2- Spatial system consists of many systems as follows:

- Functional System: "users' requirements - activity requirements - dimensional requirements furnishing requirements."

- Environment Comfort System: "climatic comfort - lighting comfort - acoustical comfort."

- Structural System: "building materials - structural patterns - economic efficiency - building technology."

- Aesthetic System: "emotional aesthetics - aesthetics thought - sensuous aesthetics."

3- Physical components of structural system are: (building materials - structural patterns - building technology).

4- Relationship between the spatial and structural systems is identified in three key elements, which are: 


\section{THE EFFECT OF STRUCTURAL ELEMENTS ON THE INTERIOR ARCHITECTURAL SPACE}

- Structural requirements that contain nine points of relevance.

- Physical requirements that contain sixteen points of relevance.

- Aesthetic requirements that contain eighteen points of relevance.

5- The historical relationship between structural system and interior architecture space was monitored and documented according to the different periods of thinking.

6- Structural patterns was classified into five key patterns according to the type of stress, which are: (Form active structure systems - Vector-active structure systems - Bulk active structure systems Surface-Active Structure system - Vertical Structure system).

7- Samples obtained an average percentage of $82.5 \%$ by being evaluated using the form. This means the possibility of applying this form in practical life.

\section{6-2- Recommendation:}

1- The importance of using the evaluation form in the comparison of various alternative solutions for any suggested project to identify the most suitable alternative solutions and determine the defects in each suggested solution.

2- Formation of the evaluation committee of experts to monitor and document the relationship between structure and interior space in current buildings to determine the performance level as this form is considered one of the classification standards of architectural facilities.

3- Account is taken of the evaluation form in the legislations and governing laws of building in order to improve the interior architectural environment.

4- The importance of the establishment of an interactive sharing principle to help in the architect's process of structural decision taking in terms of the adequacy of structural system with the architectural thinking of space in addition to convincing the Civil Engineer of the value of his role in activating the architectural selection in a manner that suits him economically with loads to participate in the success of spatial system.

5- The importance of following up with the international thought based on the integration between architecture and structure through providing the scientific resources, direct contact, and scientific sharing.

6- Encourage and support the input of modern technology in structure "in terms of implementation methods, development of modern materials leading to a continuous support to industry in order to promote and raise the local architectural level.

7- Conducting research studies in other components of the spatial system shall be taken into account, in order to suggest an evaluation form for each component of the components in this system. Thus, the efficiency of the spatial system can be judged from all aspects not only the structural aspect.

8- Conduct a research study for the possibility of transforming this evaluation study into program to be used in computers, where required data can be input. Then the program can perform the analysis process and conclude the required data and feeding it with information about structural patterns and their economical limits to contribute in selecting the suitable system along with its alternatives.

9- Future research studies might address developing a scientific approach about how to solve each point of the weakness points found by the evaluation form in the relationship between structure and interior architectural space.

\section{REFERENCES}

1. A.Blanc\&M.Mcevoy\&R.plank: "Architecture \& Construction in Steel -E\&FN Spon,London,1993c.

2. Ali Raafat: Construction Innovation in Architecture - Triple architectural creativity - Inter Consult Research Center, Al-Ahram Press, Cairo.

3. Andrew W. Charleson: Structure as Architecture, An imprint of Elsevier, Oxford, first edition ,2005

4. Engel ,Heino :Structure systems, DVA,University of Minnesota,1965

5. Francis DK Ching :Building Construction Illustrated, third edition ,john wiley\&sons , Inc-Canada , 2001

6. Francis DK.Ching :Interior Design Illustrated, Van Nostrand, Reinhold, New York 1983.

7. Hend alsaid Osman: space energy and total thermal comfort - PhD -arch departmentFaculty of Engineering, Cairo University, 2004. 
8. Irfan Sami: "functional theory in the architecture," Knowledge House in egypt- 1966.

9. Mohammed Mahmoud Oweida: "Modern technology in construction" -dar Arab renaissance for printing and publishing- Beirut -1984 .

10. Murad Abdul Qadir: the evolution of the concept of architectural space- msc- arch department- Faculty of Engineering, Cairo University -1972.

11. Mustafa Adli Baghdadi "Changing Ideals In Architecture" - The Third International Scientific Conference- al Azhar University Faculty of Engineering, 1993.

12. Omar bin al-Hashemi, "the impact of modern technology on the composition of architectural facades in the Arab world" msc - Department of Architecture, Faculty of Engineering, Cairo University -2000.

13. Tarek Mohammed Jamal: visual pollution and urban legislation in Egypt, msc, Faculty of Engineering, Cairo University, 1995.

14. Yahya Abdullah : Theory of Architecture lectures - second year - Arch Department Faculty of Fine Arts - Helwan University.

15. http://www.arcspace.com/architects/grimshow/space_centre

16. http://www.baliparkssofbaseball.com/al/skydome.htm

17. http://www.eren.doe.gov-buildings/lecture

18. http://www.greatbuildings.com/types.html 